\title{
EXPERIMENTAL PULMONARY HYPERTENSION
}

\author{
BY \\ A. VAN BOGAERT AND R. TOSETTI* \\ From the Institut Bunge, Berchem-Antwerp, Belgium, and the Pathological Service of the Blalock Centre, University of \\ Turin, Italy \\ Received October 10, 1962
}

In order to demonstrate experimentally and conclusively the existence of pulmonary arterial vasomotor control it is necessary that changes in pressure should be produced in the absence of any change in left or right ventricular output. This essential condition demands experimental conditions that are particularly difficult to achieve in the intact animal. In isolated organs it is more easily realized, but the risk of anatomical and functional nervous disturbances endangers the certainty and precision of the conclusions drawn from such experiments.

Here we report three groups of experiments carried out on the dog, with the object of presenting facts that seem to provide convincing evidence of the existence of pulmonary arteriolar and venular vasoconstrictor reflexes. That variations in cardiac output occur in the course of such different types of experiments certainly cannot be doubted, but we believe that it is permissible to ignore them as far as the direct ætiological factor of the arterial or venous hypertension is concerned, for reasons that we will give in due course as each of them are encountered.

Since 1952, with our collaborators Van Genabeek, Van Dael, Fannes, Van der Henst, Arnoldy, and van Duffel, we have carried out three types of experiment aimed at provoking and establishing a permanent arterial pulmonary hypertension in the dog. These were chronologically: (1) ligation of one or several pulmonary veins (van Bogaert et al., 1953); (2) permanent left atrial hypertension obtained by a left aortico-atrial anastomosis (van Bogaert et al., 1957); and (3) experimental silicosis (van Bogaert et al., 1960).

\section{Ligation of One or Several Pulmonary Veins}

In our first group of experiments we sought to determine whether an obstruction placed on the pathway of blood from the pulmonary veins would give rise to hypertension above the obstruction (van Bogaert et al., 1953). With the second we tied the pulmonary vein of the single inferior pulmonary lobe, e.g. on the left side, into the entrance of the left atrium and recorded the reaction of the arterial pressure in the contralateral hilar artery, i.e. in this case the right hilar artery.

We obtained under these conditions an immediate moderate rise in pulmonary arterial pressure, which might amount to double the initial value. Ligation of the pulmonary veins of the upper and middle lobes was less effective than ligation of the single inferior lobar vein, but ligation of the three veins, i.e. of an entire lung, was the most effective. The reaction of the pressure was principally on the systolic but also on the mean pressure, without modification in the cardiac frequency.

The fluctuating character of the hypertensive reaction, its absence in certain animals, its proportionality to some extent to the surface excluded, and finally its disappearance immediately after release of the ligature have encouraged certain authors (Denolin, Courtoy, and Dumont, 1957) to

* Work carried out with the help of the Fonds National de la Recherche Médicale and the Fonds Cardiologique "Groupe Comte de Launoit" and of Grant No. H 60/2 of the National Institutes of Health. 
regard it as a hypertension that is strictly passive and secondary to the simple introduction of an obstacle to the venous blood flow towards the left side of the heart.

This criticism would be justified if one could ignore the fact that ligation of the single inferior lobar vein is more effective in producing hypertension than the ligation of the veins of the two other lobes and that its effect can sometimes be absent after the exclusion of an entire lung. In addition it would have been necessary to ignore the well-established fact that the healthy pulmonary vascular bed can double and even treble the normal output without an increase in the pulmonary arterial pressure.

It was, however, the behaviour of the pulmonary arterial pressure in the animals with tied veins that were kept under observation for several weeks, rather than the characteristics of this immediate reaction, that led us to believe in an active vasomotor mechanism.

In the majority of our animals, the pulmonary arterial pressure reached its maximum between the eighth and fifteenth day after ligation. In one animal it reached $70 / 30 \mathrm{~mm}$. $\mathrm{Hg}$ instead of the $30 / 15 \mathrm{~mm}$. Hg before ligation. However, it was curious to note that this hypertension, although considerable, disappeared in the weeks that followed. After 30 to 40 days the pressure had returned to its normal level (Table I).

TABLE I

Pulmonary Arterial Pressures in Ten Dogs After ligation of Pulmonary Veins

\begin{tabular}{|c|c|c|c|c|c|c|c|c|c|c|c|}
\hline \multicolumn{2}{|c|}{ Dog No. } & 1 & 2 & 3 & 4 & 5 & 6 & 7 & 8 & 9 & 10 \\
\hline $\begin{array}{l}\text { Before } \\
\text { During } \\
\text { After } \\
3 \text { days . } \\
8 \text { days . } \\
15 \text { days . } \\
21 \text { days . } \\
26 \text { days . } \\
28 \text { days . } \\
33 \text { days . } \\
40 \text { days . }\end{array}$ & $\begin{array}{l}\ldots \\
\ldots \\
\ldots \\
\cdots \\
\cdots \\
\ldots \\
\ldots \\
\ldots \\
\ldots\end{array}$ & $\begin{array}{c}70 / 30 \\
40 / 14 \\
30 / 10 \\
30 / 10\end{array}$ & $\begin{array}{l}30 / 10 \\
32 / 10\end{array}$ & $\begin{array}{l}34 / 5 \\
28 / 8\end{array}$ & $\begin{array}{l}40 / 24 \\
40 / 10\end{array}$ & $\begin{array}{l}20 / 12 \\
40 / 15\end{array}$ & $\begin{array}{l}28 / 10 \\
30 / 14 \\
\\
28 / 8 \\
25 / 10 \\
22 / 8\end{array}$ & $\begin{array}{l}30 / 10 \\
28 / 12\end{array}$ & $\begin{array}{l}30 / 12 \\
28 / 10 \\
22 / 8\end{array}$ & $\begin{array}{l}20 / 6 \\
35 / 10 \\
40 / 15 \\
38 / 10 \\
30 / 12\end{array}$ & $\begin{array}{l}15 / 8 \\
25 / 14 \\
45 / 18 \\
45 / 18\end{array}$ \\
\hline
\end{tabular}

Other authors studying the influence of pulmonary vein ligation on the pulmonary circulation, who had maintained a strictly anatomical point of view, had shown that rapidly and always within three months the pulmonary circulation under these circumstances had regained normal behaviour within limits of 80 per cent, by some corrective or compensatory pulmono-azygos-caval system (Ameuille, Lemoine, and Nouaille, 1938).

Encouraged and supported by these anatomical observations, we have interpreted our hæmodynamic observations as follows: after a period of venous distension has caused a rise of arterial pressure, at first partially passive but later active, the vasoconstrictor excitation is suppressed by the reestablishment of the venous circulation by compensatory collaterals that reduce the venous distension. The absence of an exact correction immediately after the exclusion of a single lobe or of the entire lung, with the resultant slight increase in tension, appears to us to be already the first expression of this early arterial and venous constriction, secondary to the distension. This immediate reaction, wrongly considered we believe as passive, increases in the following days and reaches in certain animals figures too high $(70 / 30 \mathrm{~mm} . \mathrm{Hg})$ to be considered passive.

The recent research of Carlier and Lejeune-Ledant (1959) has shown that the pulmonary veins near their atrial openings enclose presso-sensitive zones showing their activity by action currents: anæsthesia inhibits these pressure-receptor nerve endings. Rovati (1956) and others have shown the sensitizing action of sympathomimetics on this arterial hypertensive reaction, but they have not been able to confirm its elimination by section of the vagus. 
After establishing on a solid basis the existence of reflex pulmonary arterial vasoconstriction, it seemed essential to seek a more durable mechanism of venous distension, neither corrected nor compensated by appeal systems, which would allow us to study on the one hand the anatomical reactions of the arteriovenous tree and on the other hand its reactive modalities to the distension. We have therefore made use of a delicate technique, i.e. the lateral anastomosis of the thoracic aorta to the point of the left auricle (van Bogaert et al., 1957).

\section{Permanent Left Atrial Hypertension by Direct Anastomosis with the Aorta}

The most delicate feature of this technique, which is so effective and rich in pathological sequelæ, is the achievement of a shunt, the output of which appears to be well tolerated. If the output is too large the left side of the heart rapidly dilates and during the operation ventricular fibrillation occurs. The left atrial pressure, under these circumstances, rises rapidly to $30 \mathrm{~mm}$. $\mathrm{Hg}$.

If the output is apparently well tolerated during the operation one can see three types of delayed reaction, which may be classified as follows.

Group 1. Survival did not exceed 8 to 21 days and death supervened suddenly from pulmonary œdema: this occurred in 9 out of 19 dogs. Their capillary pressure was generally increased towards the tenth day to double and even quadruple the normal.

Group 2. The capillary pressure, momentarily doubled, returned to normal: these were the dogs in which the shunt was too narrow and therefore ineffective.

Group 3. The capillary pressure, at least doubled, became stabilized at this level, remained so for a few weeks, and then progressively increased after two or more months, up to 20, 25 and 30 $\mathrm{mm}$. Hg. During two to seven months, three dogs showing this type of reaction have been kept alive. These dogs, forming Group 3, have obviously provided most of the interesting information for the problem with which we are concerned.

In Group 1-the animals dying early from pulmonary œdema with capillary pressure rising rapidly to high levels - the pulmonary arterial pressure increased to 35 to $40 \mathrm{~mm}$. $\mathrm{Hg}$ for the maximum and 20 to $25 \mathrm{~mm}$. Hg for the minimum. At autopsy they presented gross arteriolar and

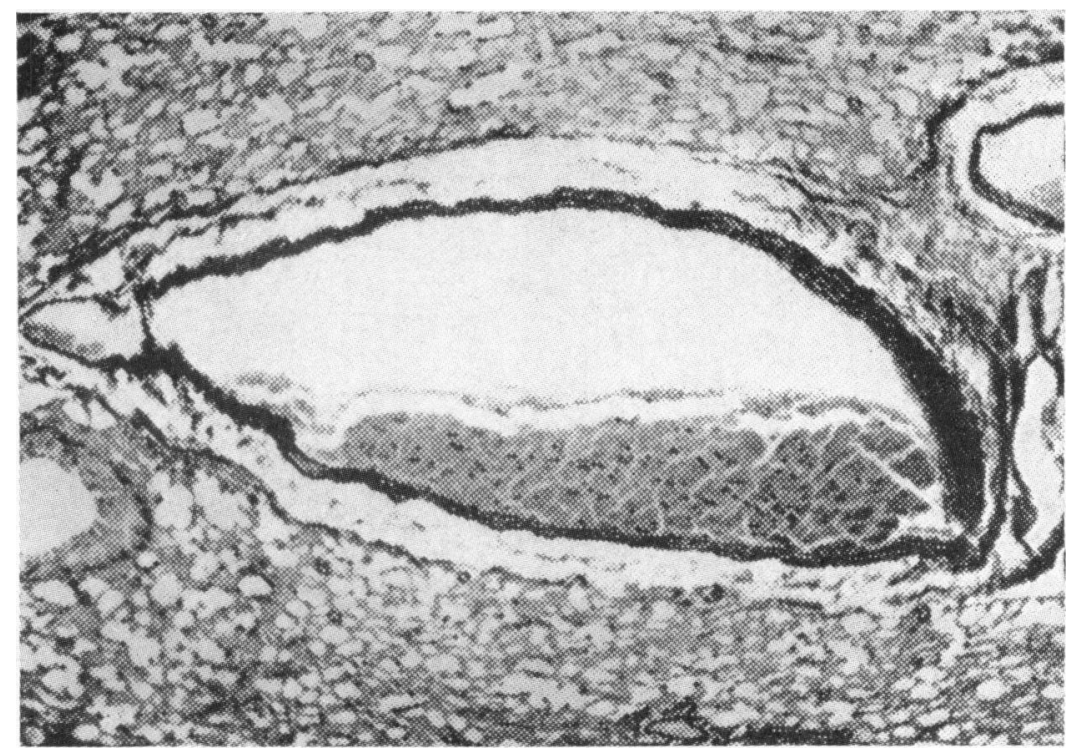

Fig. 1.-Dog 6: distended arteriole, engorged with blood and partially thrombosed. 


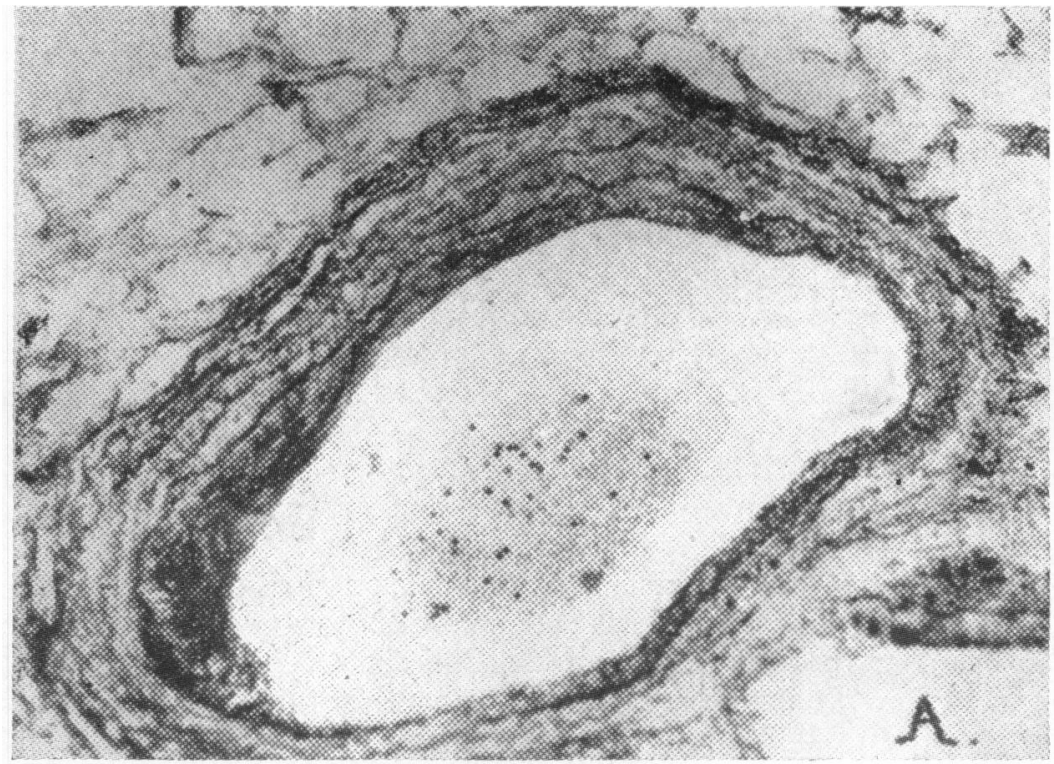

(A)

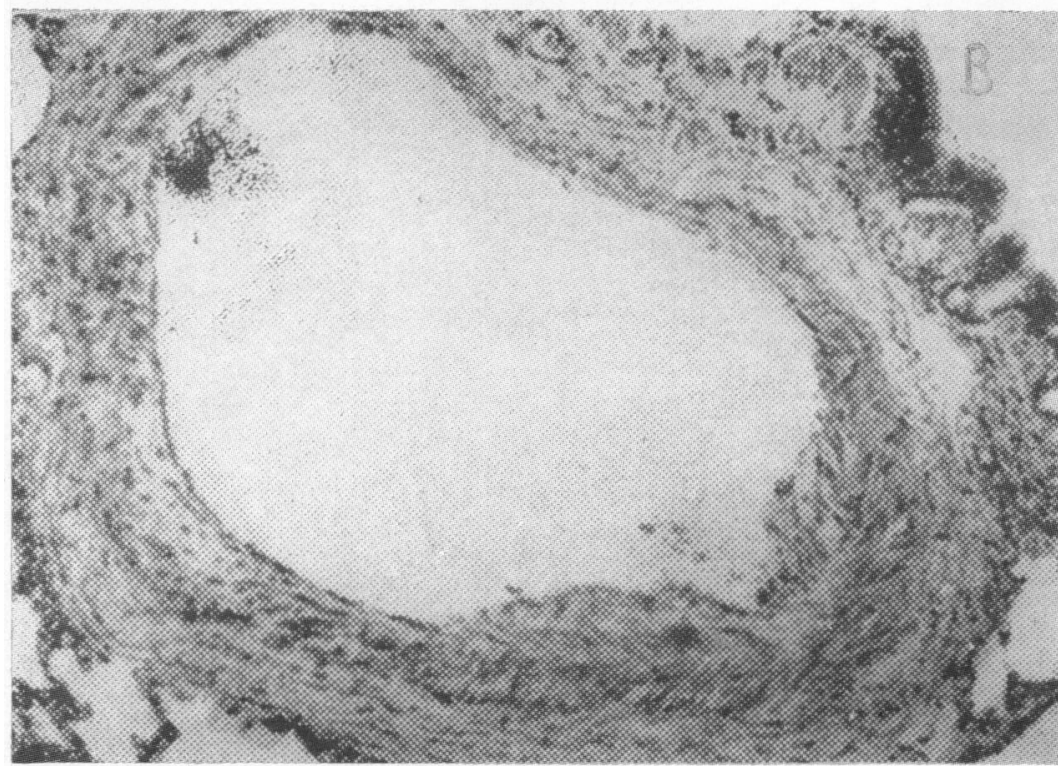

(B)

FIG. 2.-Dog 1: arteriole of $700 \mu$. Showing hypertrophy of media with increase in elastic lamella. Kernohan index $1 / 1 \cdot 3$. (A) Weigert elastic. (B) Hæmatoxylin and eosin. 
venular dilatation (vessels of 50 to $1000 \mu$ ). Their Kernohan index reached 1/14 to 1/20 (n: 1/8). Some veins were very distended so that they had become varicose. They were engorged with blood and some were thrombosed. Similar findings were encountered in the arterioles (Fig. 1). On the other hand the venular and arteriolar muscular elastic walls were not altered.

The three animals of Group 3 survived more than two months, in spite of a severe though welltolerated shunt. The pulmonary arterial pressures were as follows: $125 / 50 \mathrm{~mm}$. $\mathrm{Hg}$; capillary pressure, $25 \mathrm{~mm}$. telediastolic ( $\operatorname{dog} 1)-80 / 40 \mathrm{~mm}$. $\mathrm{Hg}$; capillary pressure, $30 \mathrm{~mm}$. $\mathrm{Hg}$ telediastolic (dog 3)-50/22 mm. Hg; capillary pressure, $22 \mathrm{~mm}$. Hg telediastolic (dog 14).

After seven months' survival histological examination showed the following in the most hypertensive $\operatorname{dog}(\operatorname{dog} 1)$. (a) A severe reduction in the lumen of the arteriolar vessels $(700 \mu)$ and of the venules $(250 \mu)$. The Kernohan index decreased to $1 / 3$ and $1 / 4$. (b) The arteriolar and venular media was severely hypertrophied through development of the muscular layers of the arteriolar media and of the venous subintimal layer. In addition, the number of elastic lamellæ was increased. This was particularly striking in the venules (Fig. 2). (c) The venous pre-capillaries of 50 to $80 \mu$ normally limited by a subendothelial layer without obvious muscular substructure showed a welldeveloped and spastic muscular layer (Fig. 3).

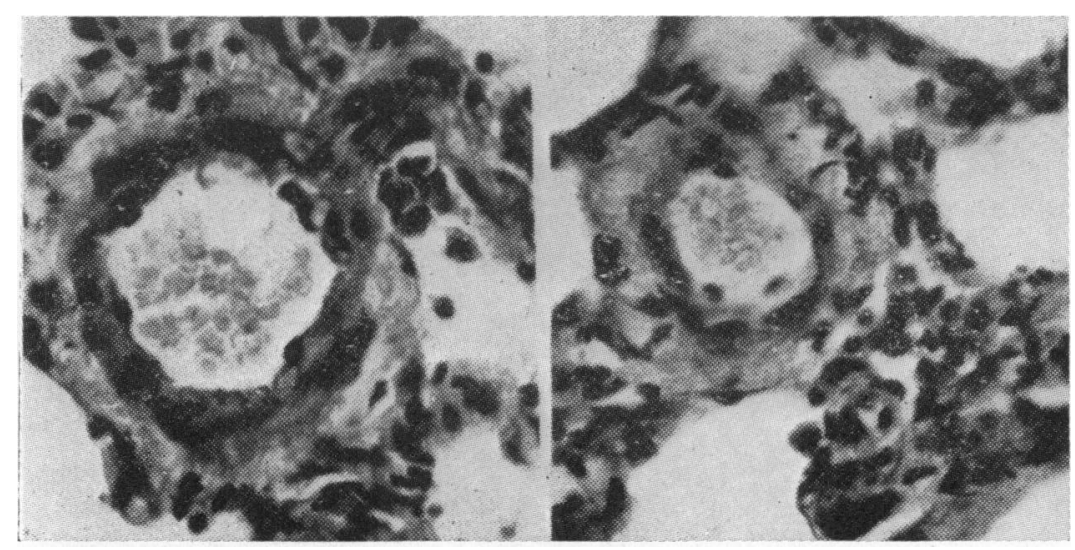

FIG. 3.-Venous pre-capillaries of 50 to $80 \mu$ : well-developed and spastic muscular layer in the subendothelium.

In one of these animals ( $\operatorname{dog} 3$ ), dying from pulmonary œdema towards the end of the second month, with a hypertension of $80 / 40$ and a capillary pressure of $30 \mathrm{~mm}$. $\mathrm{Hg}$, there were numerous old and recent pre-capillary thromboses, but the arteriolar musculo-elastic walls were scarcely hypertrophied. By contrast, those of the venules showed an obvious hypertrophy (Fig. 4). Similar appearances were encountered in dog 14, dying after four months with a pulmonary arterial pressure of $50 / 22 \mathrm{~mm}$. $\mathrm{Hg}$ and without an arterio-capillary gradient (capillary pressure, $22 \mathrm{~mm}$.). The arterial walls in this animal were almost normal, but the walls of the veins of 50 to $100 \mu$ were narrowed (index 1/3). Some veins were thrombosed, but those that were not thrombosed also showed a severe muscular hypertrophy (Fig. 5).

These experiments confirm the fact that distension of the venous limb of the pulmonary vascular tree determines, as we have already seen from our experiments with venous ligation, an arterial hypertension considerably greater than that which would be consistent with simple mechanical obstruction passively raising the pulmonary arterial pressure. These experiments have also revealed new facts and have made possible increased precision as to the types of reaction.

(i) Venous distension accompanied by venous hypertension gives rise to an early moderate arterial hypertension, without arteriovenous gradient, in short an apparently passive hypertension. 
(ii) After a delay that varies from one subject to another but lasts at least two months, this venous hypertension is accompanied at first by a reaction of musculo-elastic hypertrophy of the venous walls. At this stage the arterial pressure is increased, but there is still no arteriovenous gradient. This observation shows then that the absence of a gradient does not permit one to assert that the arterial hypertension is passive. It allows only the localization of the obstruction

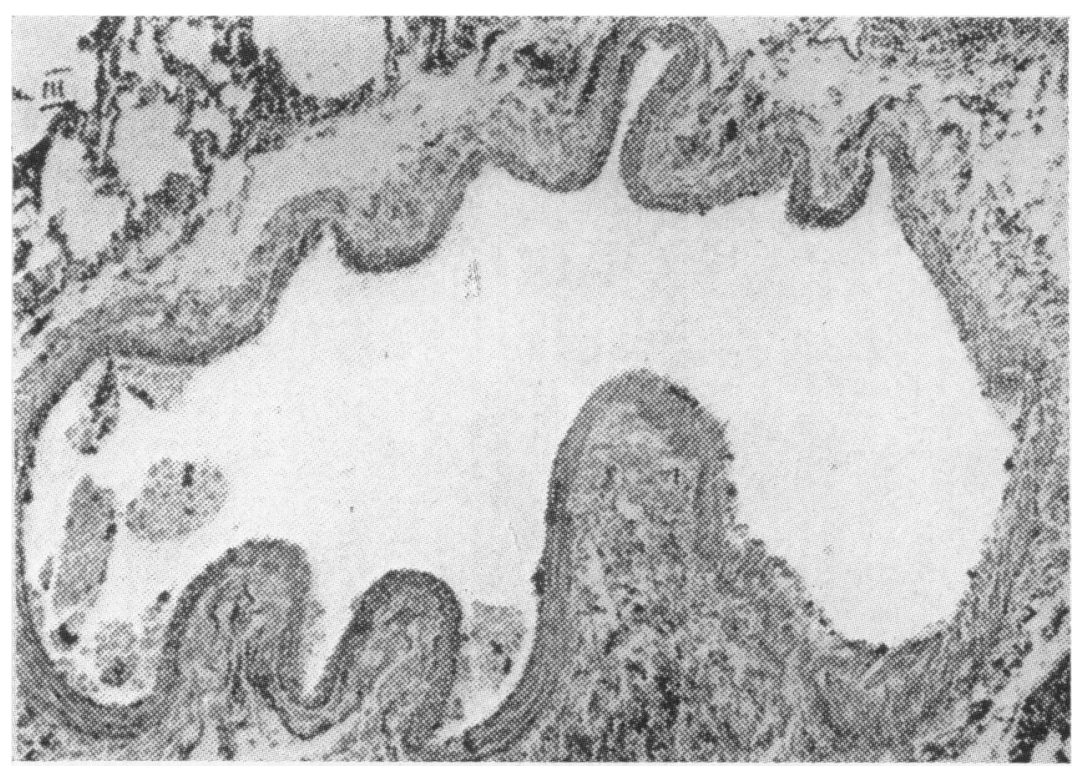

FIG. 4.-Dog 3: venule of $1000 \mu$. Showing hypertrophy of wall.

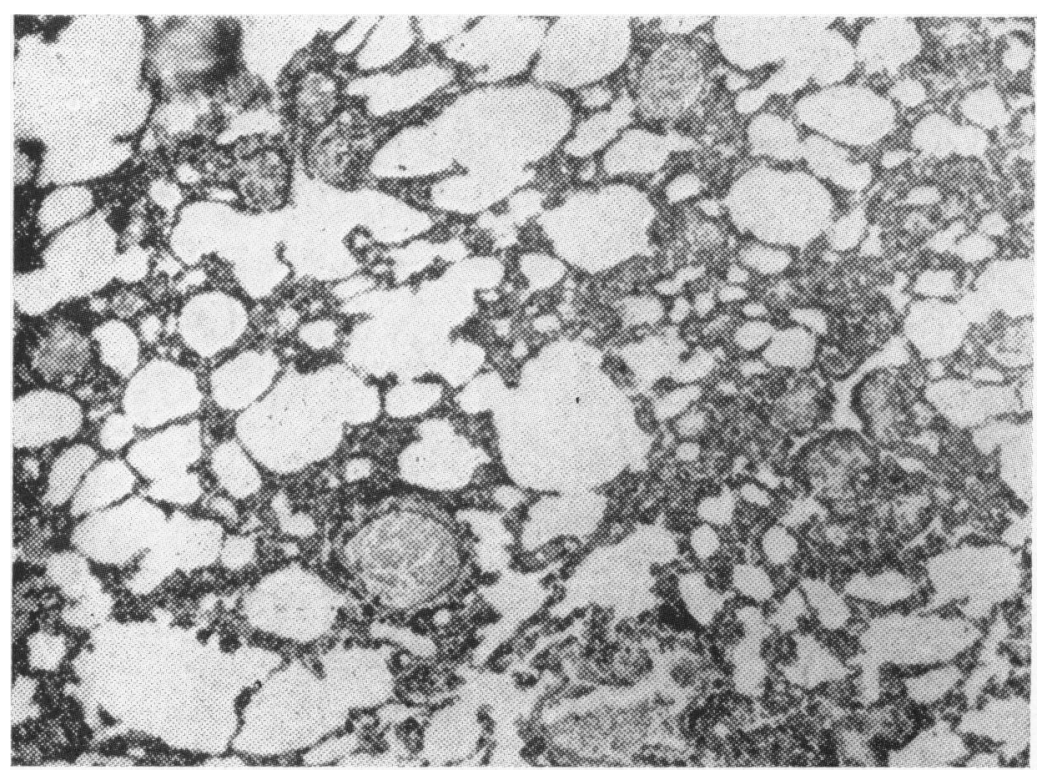

FIG. 5.-Dog 14: thrombosed veins. 
to the venous post-capillary limb of the pulmonary vascular tree, without permitting precision as to its nature.

(iii) Venous hypertrophy is followed later by a musculo-elastic hypertrophy of the arteriolar walls. At this stage the figures for the pulmonary arterial pressure are higher and there is an arteriovenous gradient. The animal, at this stage, dies from myocardial insufficiency.

We have tried to establish whether the venous contractile reaction, which we have invoked as the first reaction to distension, really exists; and with this in mind we introduced by the pulmonary hilum a slender sound into a pulmonary arteriole, and the catheterized artery was tied around this sound. In this manner a vascular segment was isolated from any influence above, the only blood still reaching it being that from the left atrium, in a retrograde manner, and the blood of the bronchial arteries anastomosing with the capillary plexus in the pulmonary lobule. If the pressure in the left atrium is increased suddenly by an atrio-aortic shunt, the pressure in the left atrium and in the pre-capillary plexus increase in parallel and to an equal extent (Fig. 6). However, if the atrial pressure is increased progressively and in a moderate manner, the pressure in the pre-capillary segment increases more than in the left atrium (Fig. 7). There is then a dissociation between the atrial and pre-capillary pressure reactions. The pulmonary diastolic pressure follows the

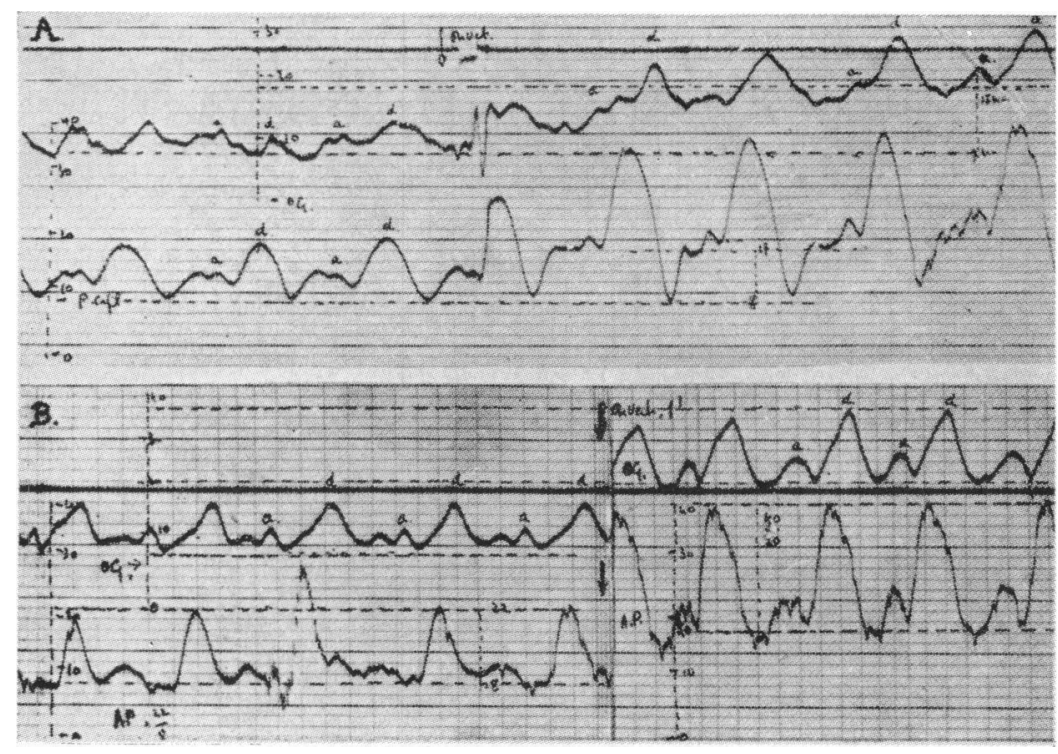

Fig. 6.-See text, above.

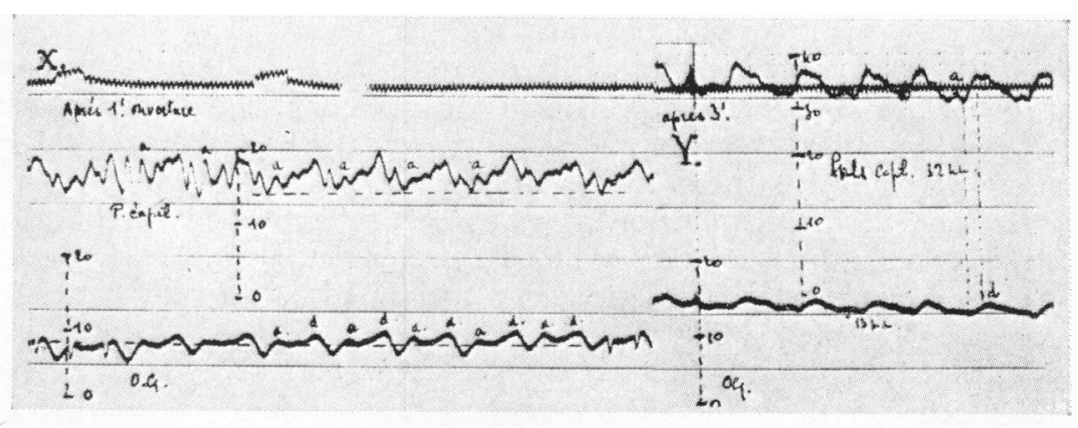

Fig. 7.-See text, above. 
pre-capillary pressure. Such a dissociation can only be conceived if a mechanism of venous vasoconstriction exists, interposed between the capillary plexus and the left atrium or the entrance of the pulmonary vein into the left atrium.

This venous vasoconstrictor mechanism seems concordant when the left atrial pressure rises too suddenly and too strongly. Such a venous arteriolar vasoplegia predisposes to pulmonary œdema and equally to the thromboses that were so frequent in those animals dying early as the result of shunts that were too large and poorly tolerated.

These experiments, therefore, have yielded interesting information on the real role of venous distension as a factor determining active pulmonary arterial hypertension. They show, in addition, that the reaction is principally brought about by a reflex with a short arc, as indicated apparently by the previous occurrence of the functional and then the anatomical reaction of the most distended and most distensible vessels, i.e. the pulmonary veins.

The arterioles, later and more moderately distended because of the interposition of the capillary plexus, also hypertrophy last. In the stage of venous constriction the pulmonary arterial pressure increases moderately in general but sometimes rather strongly, though the arteriovenous gradient is absent or very small. The pressure increases considerably and with the appearance of a gradient if an active reduction of the calibre of the vessels of the pre-capillary limb is added.

The influence of a degree of change in the cardiac output on the appearance of hypertension in our animals could be excluded since we have observed them for a prolonged period after the creation of the arteriovenous shunt. This certainly increases the cardiac output suddenly while the pulmonary arterial pressure only becomes established progressively. The latter is increased later, in spite of the secondary decrease in output from the severe myocardial insufficiency observed in certain of our animals.

In spite of these facts, showing with certainty the existence of an active vasoconstrictor reaction of the pulmonary vascular tree to distension, it has seemed essential to investigate the causal element of the venous and arterial constriction and the muscular media hypertrophy that followed it. Was it venous hypertension or the abnormal simple tension of the venous wall from an increasing volume of stagnant blood? This is a question to which experimental silicosis (van Bogaert et al., 1960) has enabled us to provide an answer.

\section{EXPERIMENTAL SiLICOSIS}

We have been able to produce a silicosis in the dog that is anatomically and in terms of pulmonary function identical with that occurring in miners working on rocks rich in quartz. In spite of considerable losses as a result of technique we have been able to keep four dogs alive for three years or more. Table II summarizes the hæmodynamic and oximetric findings obtained in the course of these experiments.

At the end of the period of induction of silicosis venous angiography showed amputation of the terminal part of the arterial vascular tree (Fig. 8). The histological study of the pulmonary vessels has shown the following points.

(i) In dogs dying early without pulmonary arterial hypertension there was a massive vasodilatation with venular and arteriolar thromboses (Fig. 9). A similar appearance was present at the end of the first year of silicization in lobar biopsies (van Bogaert et al., 1953) made in dogs that have later shown hypertension but at that time, in spite of the extensive thromboses, had a pressure scarcely higher than normal, i.e. from 35 to $40 \mathrm{~mm}$. $\mathrm{Hg}$.

(ii) At this first stage of vasoplegia with thromboses an adventitial reaction can be seen. The adventitia is thicker than normal and sometimes its constituent elements are dissociated. One can also see a discrete hypertrophy of the muscular coat of the veins with total absence of any reaction of the media of the arteries (Fig. 10).

(iii) In dogs killed after three or four years and showing a pulmonary arterial hypertension for several months, the Kernohan index was always very large $(1 / 0 \cdot 7-1 / 0 \cdot 8)$. Spasticity of the muscular coat of the small arteries was present, and in particular considerable thickening of the adventitia 
TABLE II

HÆmodynamic and Oximetric Findings in the Course of Experimental Silicosis in Dogs

\begin{tabular}{|c|c|c|c|c|c|c|c|c|}
\hline $\begin{array}{l}\text { Dog } \\
\text { No. }\end{array}$ & & $\begin{array}{l}\text { Oct. } \\
1956\end{array}$ & $\begin{array}{l}\text { Nov. } \\
1956\end{array}$ & $\begin{array}{l}\text { Sept. } \\
1957\end{array}$ & $\begin{array}{l}\text { Dec. } \\
1958\end{array}$ & $\begin{array}{l}\text { June } \\
1959\end{array}$ & $\begin{array}{l}\text { April } \\
1960\end{array}$ & $\mathrm{O}_{2} \%$ \\
\hline $4^{*}$ & $\begin{array}{l}\text { Pulmonary capillary pressure }(\mathrm{mm} . \mathrm{Hg}) \\
\text { Arterial pressure }(\mathrm{mm} . \mathrm{Hg})\end{array}$ & $\stackrel{4}{35 / 10}$ & $\stackrel{4}{35 / 10}$ & $\begin{array}{c}11 \\
35 / 12\end{array}$ & $\begin{array}{l}13 \\
+ \\
40 / 16\end{array}$ & $\begin{array}{c}18 \\
50 / 20\end{array}$ & $\begin{array}{c}5 \\
50 / 14\end{array}$ & 91 \\
\hline $12 \dagger$ & $\begin{array}{l}\text { Pulmonary capillary pressure }(\mathrm{mm} . \mathrm{Hg}) \\
\text { Arterial pressure }(\mathrm{mm} . \mathrm{Hg})\end{array}$ & & $3 \overline{30 / 12}$ & $\begin{array}{c}10 \\
40 / 10\end{array}$ & $\stackrel{8}{30 / 12}$ & & $\stackrel{9}{9}$ & 91 \\
\hline $15 \ddagger$ & $\begin{array}{l}\text { Pulmonary capillary pressure }(\mathrm{mm} . \mathrm{Hg}) \\
\text { Arterial pressure }(\mathrm{mm} . \mathrm{Hg})\end{array}$ & & $3 \overline{5 / 10}$ & $\begin{array}{c}16 \\
40 / 16\end{array}$ & $\begin{array}{c}18 \\
40 / 15\end{array}$ & $\begin{array}{c}4-6 \\
55 / 22\end{array}$ & & 85 \\
\hline $26 \S$ & $\begin{array}{l}\text { Pulmonary capillary pressure }(\mathrm{mm} . \mathrm{Hg}) \\
\text { Arterial pressure }(\mathrm{mm} . \mathrm{Hg})\end{array}$ & & & & $\stackrel{8}{35 / 12}$ & $\begin{array}{c}12 \\
42 / 12\end{array}$ & $\stackrel{6}{75 / 25}$ & 95 \\
\hline
\end{tabular}

* First injected with silicosis in October 1956.

$\uparrow$ First injected with silicosis in November 1956.

First injected with silicosis in December 1956.

$\S$ First injected with silicosis in January 1958.

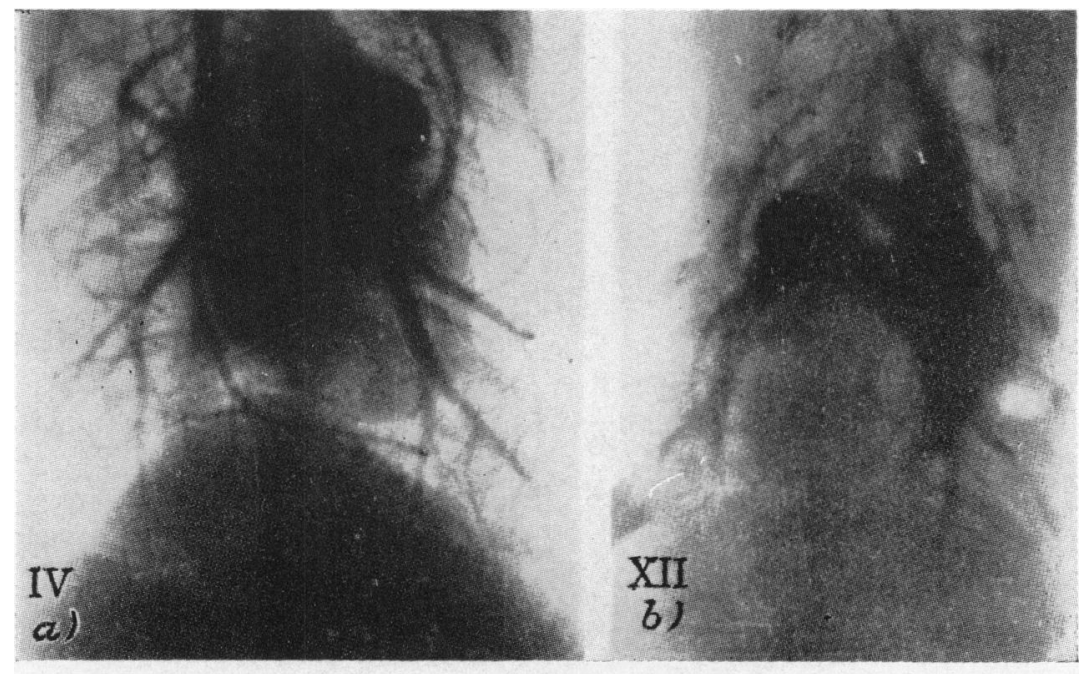

FIG. 8.-Angiographic aspect of the pulmonary tree after experimental silicosis.

with very pronounced fibro-elastosis, and especially hyperelastosis so that a third elastic lamina was formed (Fig. 11, 12). The arteriolar muscle fibres had undergone hyaline degeneration.

We have carried out biopsies on the right median lobe (little developed in the dog) in order not to reduce the pulmonary vascular surface too much. The bronchial arteries were affected to the same degree as the pulmonary arterioles. The pre-capillaries of 20 to $150 \mu$ were often thrombosed as were also the post-capillary venules of $40 \mu$. The capillaries were very much changed. All the lesions were most severe in the most silicotic zones.

Thus in silicosis with pulmonary arterial hypertension vascular anatomical reactions exist which are very different from those observed in the course of long-standing left atrial hypertension. In effect, in silicosis, there is no hypertrophy of the arteriolar muscular media but stenosing fibroelastosis of the peri-arterial tissue; while in left atrial hypertension, the peri-arterial tissues were normal but the muscular and elastic media was greatly hypertrophied. 


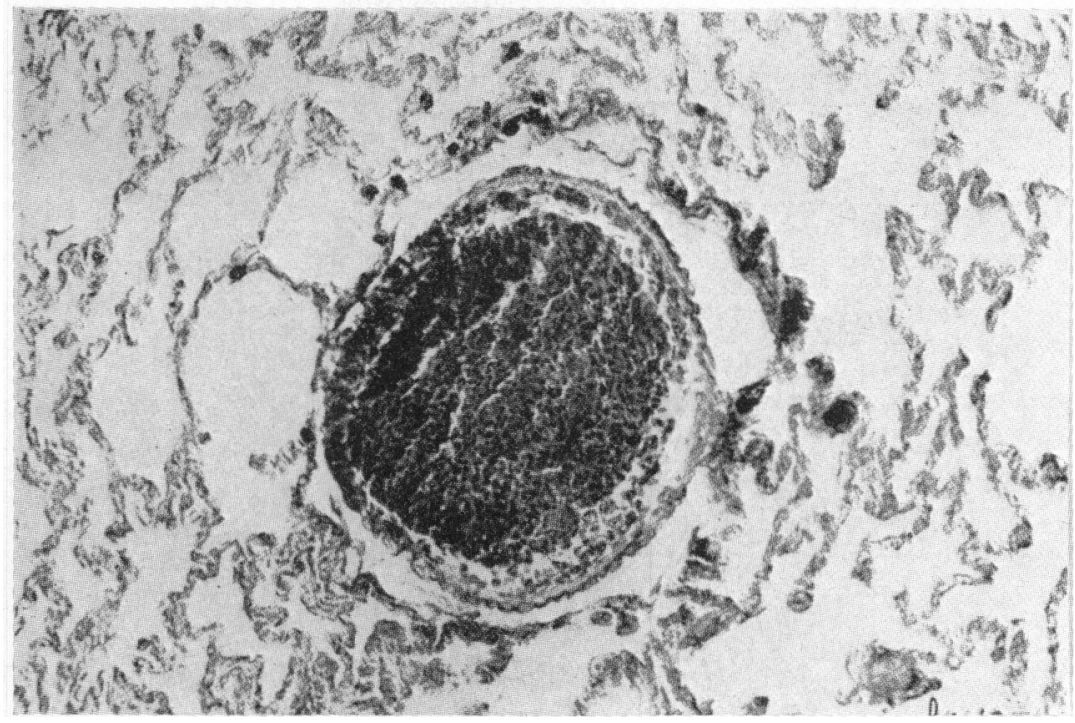

Fig. 9.-Dog 4: venule of $200 \mu$ by silicosis, with thrombosis. Kernohan index 1/10.

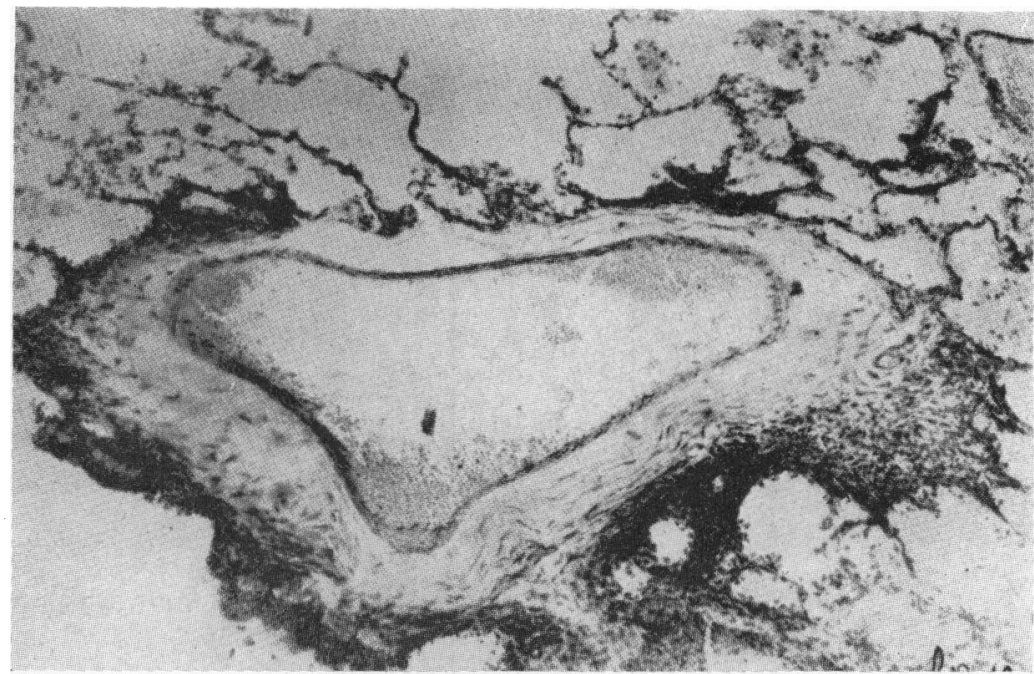

FIG. 10.-Dog 16: total absence of reaction in media of artery. Hæmatoxylin and eosin.

On the other hand the two experimental conditions present certain points in common: (i) venous and arteriolar dilatation with frequent initial thrombosis; and (ii) the early appearance in silicosis as also in atrial venous hypertension of hypertrophy of the venous muscular coat. In both cases, the passive veno-arterial distension-mechanical in left atrial hypertension and paralytic in silicosis (van Bogaert et al., 1953) — creates a circulatory slowing that favours the development of pre- and post-capillary thrombi.

At this stage a slight rise in arterial pressure can exist, which is evidence of obstruction to arterial blood flow towards the venous system and is proportional to it. But even admitting that powers of 


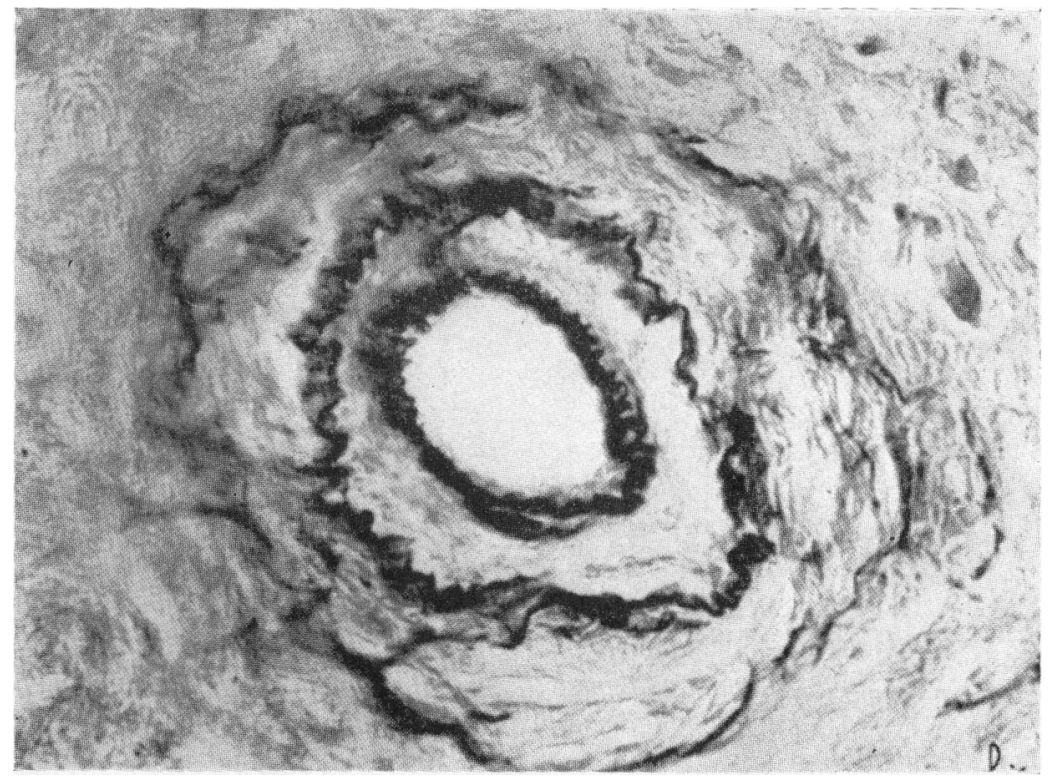

Fig. 11.-Arteriole of $110 \mu$ with a third elastic lamina. Kernohan index 1/1·1.

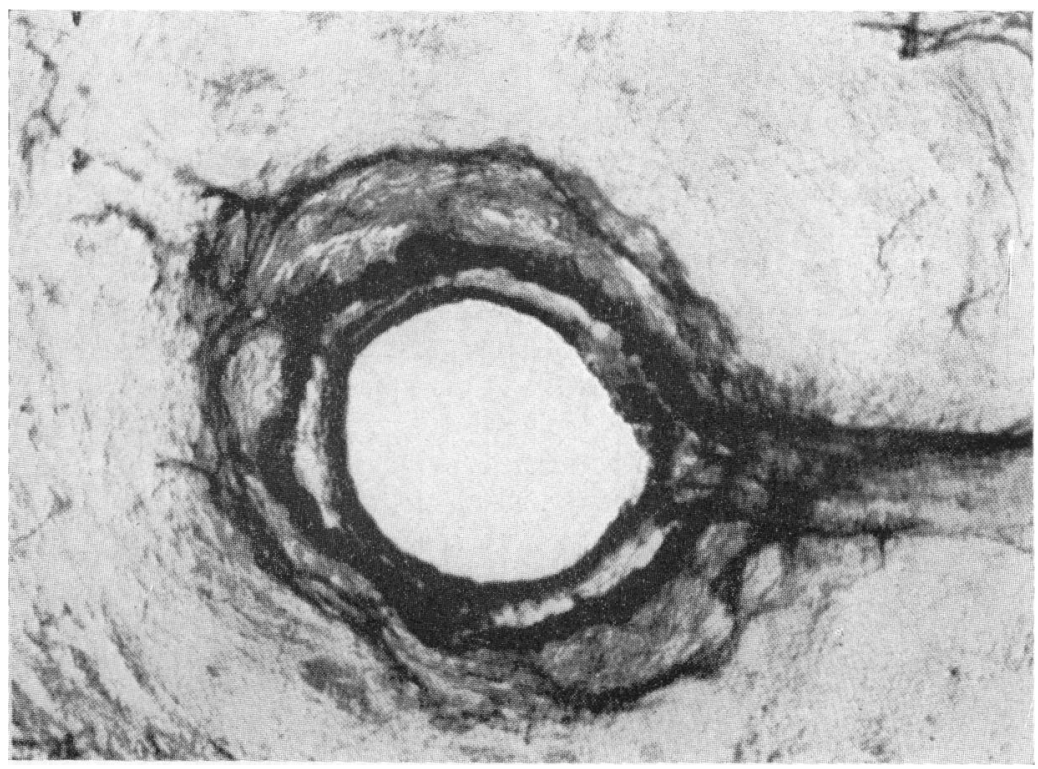

Fig. 12.-Arteriole of $220 \mu$ with a third elastic lamina. Kernohan index 1/1·7.

adaptation by dilatation of the arterial network are altered, since thromboses are dominant in the inferior lobe, the middle and superior lobes, which are hardly altered, do not manage to adapt their capacity to the volume of blood diverted towards them. At this stage, there is no gradient in the veno-arterial zones which are freely communicating. 
In the vessels in which the paralytic distension has not caused thrombosis, the venous wall tends to arterialize, although at this stage nothing can be detected in the appearance of the arterial wall. But this is not surprising since it is easier to detect the appearance of a new structure in a previously normal area than to appreciate a quantitative change that is just beginning.

In the polarizing microscope the crystals of silicosis can be seen in the interstitial spaces. Whatever the full significance of this, it suggests that the anatomical reaction is in response to functional hyperactivity, i.e. the anatomical organization is the sequel to a functional state. Silicosis has enabled us to show how well founded this fact is in permanent left atrial hypertension, where the passive distension creates a short veno-arterial vasoconstrictor reflex, followed by hypertrophy of the musculo-elastic structure which is stimulated.

It is in the region of the veins that vasoconstrictor reflex and hypertrophy are observed earliest because muscular venous hypertrophy can be detected most easily and soonest, and the most distended segment reacts the most vigorously.

In silicosis the pulmonary arterial tension rises moderately and without gradient as a result of the recent thrombotic obstructions or capillary lesions: these at an early stage hinder the dispersal of the pulmonary blood not corrected by a compensatory vasodilatation of the healthy zones of substitution. But such a defect of corrective dilatation can only be conceived where a relative hypertonia of the veno-arterial media exists.

It might be expected under such conditions that in these animals, as in those with the ligated pulmonary veins, the pulmonary arterial pressure at the end of a certain period should return to normal, either by diminution in the cardiac output, or by the establishment of new diverted pathways, or again by exhaustion of the initial vascular hypertonia. In any case, the pulmonary arterial tension should in any event not increase progressively, as occurred in some animals kept under observation for several years.

If this is not the case it must be either that the vasoconstriction is maintained and progressively replaced by hypertrophy of the muscular media, or that a mechanism peculiar to silicosis has intervened, i.e. retractile peri-arterial fibro-elastosis. The hypertension of silicosis, and probably that of the chronic pneumopathies in general, will tend then to become anatomically irreversible, though the functional factors bound to hypercapnia and anoxæmia play an accessory role in influencing the zones that are healthy. In permanent left atrial hypertension the reactive mechanism is different except at a very advanced and late stage.

In effect the venous distension responsible for hypertrophy of the venous media is transmitted upwards across the capillary barrages. These have a braking effect for a certain time and to a certain extent. At the same time the passive arteriolar distension begins little by little to cause in its own turn a hypertensiogenic arteriolar vasoconstriction equal to the venous hypertension.

At a more advanced stage the arteriolar parietal muscular reaction can increase and exceed even that of the venous segments. The pulmonary arterial tension rises then strongly and indicates, by an arteriovenous gradient, the active participation of the arteriolar territory. This participation is variable from one person to another and depends on individual factors still unknown.

This hypertension is still reversible, often entirely, sometimes only partially, according to whether the obstruction that gives rise to the venous distension is totally or partially suppressed, but only where the fibrosclerotic or highly degenerative processes are not added to the muscular hypertrophy. In this last stage the hypertrophy, secondary to a mechanical obstruction, resembles that evoked by silicosis, at least hæmodynamically.

In the way they begin and in the way they end, these two processes of hypertension are similar. If the initial evoking mechanism in one and in the other case, i.e. the obstruction to the flow of blood towards the left side of the heart, is common to both of them and gives rise to the reactions of the pulmonary vascular tree by the same mechanism, i.e. constriction in response to distension, the stabilization of the hypertension at an advanced stage of the disease establishes itself by a different process. In the one case it is established by a peri-arterial sclerosis, in the other by a meso-arterial 
stenosis or more precisely by hypertrophy of the media secondarily replaced in certain cases by an irreversible fibrous degeneration.

Before concluding, we would like to re-emphasize the fact that the reactions of the pulmonary vascular tree are principally the expression of reflexes with a short arc resulting from the mechanical or paralytic distension of the venous and arterial walls. In proof of this is the fact that the paralytic distension of silicosis gives rise to the same reactions as the mechanical distension occurring in the course of experiments.

The distension and elongation of the constituent tissues of the vascular wall, more than the venous hypertension, constitute the direct stimulus of this constrictor reflex, since venous hypertension is deficient in the paralytic distension of silicosis.

Thus tissues of the vascular wall possess elements sensitive to their degree of elongation, i.e. tensio-receptor elements, and it is not necessary to invoke the presence of presso-receptor endings in order to explain the contraction and hypertrophy of the venous and arterial media.

Is it necessary for this to exclude the intervention in these reactions of long reflexes arising in the left atrium or the openings of the pulmonary veins into the latter? We hesitate to affirm or deny their intervention in view of the facts we have collected. The only evidence for their participation is the general pulmonary arterial hypertensive reaction initiated by perfusion under pressure of an isolated pulmonary lobe (van Bogaert et al., 1953, 1957, and 1960; Denolin et al., 1957; Carlier and Lejeune-Ledant, 1959; Robicsek, 1956; Rovati, 1956) and the experiments of Carlier and Lejeune-Ledant (1959) on the existence of presso-sensitive zones at the atrial opening of the pulmonary veins.

\section{SUMMARY}

Pulmonary arterial hypertension was induced in the dog by three different procedures: (1) ligation of one or more pulmonary veins; (2) left atrial hypertension by aortic-atrial shunt; and (3) experimental silicosis accompanied by peri-arterial adventitious stenosing sclerosis and early thrombosed capillary lesions.

It has been established that the passive or paralytic distension (by silicosis) of the venous side of the vascular tree determined at an early stage a diminution in the calibre of the venules with hypertrophy of the musculo-elastic tissue of the wall.

The reaction of the venous side preceded the same reaction at the level of the pulmonary arterial segment. This reaction of the parietal vascular tissues of the whole pulmonary tree is attributed to the distension. The reflexes at intervals resulting from the excitation of presso-receptive endings of the veins and of the juxtavenous portion of the left atrium are probably also playing a part.

\section{REFERENCES}

Ameuille, P., Lemoine, J. M., and Nouaille, J. (1938). Suppléance circulatoire par les adhérences après ligature des veines pulmonaires. Ann. Anat. path., 15, 85.

van Bogaert, A., van Duffel, J., Tosetti, R., van Genabeek, A., Arnoldy, M., Vandael, J., and de Moor, J. (1960). Silicose expérimentale chez le chien. Etude clinique électrocardiographique, hémodynamique angiographique et anatomique vasculaire. Arch. Mal. Cour, 53, 1223.

- , Fannes, E., Buytaert, L., de Munck, J., van Genabeek, A., van der Henst, H., and Vandael, J. (1953). Hypertension artérielle pulmonaire après ligature d'une ou de plusieurs veines pulmonaires. Arch. Mal. Carur, 46, 289.

,$- \frac{289 .}{-}$, Tossetti, R., van Genabeek, A., Buytaert, L., Arnoldy, M., Vandael, J., and van der Henst, H. (1957). Hypertension artérielle pulmonaire expérimentale durable chez le chien. Arch. Mal. Cour, 50, 681.

Carlier, J., and Lejeune-Ledant, G. (1959). Paroi auriculaire gauche et pressions artérielle pulmonaire et ventriculaire gauche chez le chien. Arch. int. Physiol., 67, 131.

Denolin, H., Courtoy, J., and Dumont, P. (1957). Critique de l'effet hypertensif de la ligature des pulmonaires. Soc. Belge de Cardiol. 5 mai 1957.

Robicsek, F. (1956). On the nervous regulation of compensation in mitral stenosis. Acta med. Acad. Sci. hung., 9, 1 .

Rovati, V. (1956). The nature of the reflective pulmonary hypertension induced by the ligature of the pulmonary veins. Ile Congrès Européen de Cardiologie, Stockholm 1956. 